\title{
COMUNICACIÓN Y CONVIVENCIA ESCOLAR EN LA CIUDAD DE MEDELLÍN, COLOMBIA
}

\author{
Jacqueline Duarte Duarte *
}

SÍNTESIS: Los procesos comunicativos son constitutivos de la convivencia escolar, y deben ser objeto de reflexión por parte de los actores educativos con el fin de generar ambientes más propicios para la formación integral de los estudiantes y para la construcción de una sociedad más civilizada. En este artículo se presentan los resultados parciales de una investigación sobre la convivencia escolar realizada en Medellín, Colombia, y particularmente los que corresponden a la comunicación como una de las categorías que constituyen y a su vez contribuyen a explicar esta problemática. Desde la mirada más instrumental que adjudican los actores educativos a la comunicación, hasta la más compleja relacionada con su gran densidad cultural, la comunicación aparece como un factor determinante de los procesos pedagógicos y de la convivencia escolar en una ciudad como Medellín, que viene construyendo espacios de concertación y de negociación.

SÍNTESIS: Os processos comunicativos são constitutivos da convivência escolar, e devem ser objeto de reflexão por parte dos atores educacionais, objetivando gerar ambientes mais propícios para a formação integral dos estudantes e para a construção de uma sociedade mais civilizada. Neste artigo são apresentados os resultados parciais de uma investigação sobre a convivência escolar realizada em Medellin, Colômbia, e particularmente os que correspondem à comunicação como uma das categorias componentes e, por sua vez, contribuem para explicar esta problemática. Desde o olhar mais instrumental que os atores educacionais adjudicam à comunicação até o mais complexo relacionado com sua grande densidade cultural, a comunicação aparece como um fator determinante dos processos pedagógicos e da convivência escolar em uma cidade como Medellin, que vem construindo espaços de acordos e de negociação.

* Docente de la Universidad de Antioquia. Fonoaudióloga egresada de la Universidad Nacional de Colombia, Sede Bogotá. Magíster en Desarrollo Educativo y Social, Centro Internacional de Educación y Desarrollo Humano, CINDE. 


\section{INTRODUCCIÓN}

A pesar de que existen diagnósticos sobre la situación de la convivencia escolar en Medellín ${ }^{1}$, es clara la falta de estudios sistemáticos, rigurosos y actualizados sobre el tema, que permitan lograr mayores grados de eficiencia a las intervenciones que buscan un mejor clima social en las instituciones educativas de la ciudad.

De acuerdo con lo anterior y para contar con una lectura más aproximada sobre la situación de la convivencia escolar en Medellín, la Red de Convivencia Escolar ${ }^{2}$ ha realizado una investigación cuyos resultados parciales se exponen en el presente artículo. Para la elaboración de esta investigación de tipo diagnóstica, se asumió como temática central la convivencia escolar, y como unidad de análisis y como ejes transversales las nociones y las prácticas de convivencia escolar. Algunos de los interrogantes que orientaron el trabajo fueron los siguientes. Primero, ¿cuáles son las nociones y las prácticas sobre la convivencia, la normatividad y el conflicto que transitan en las instituciones educativas de la ciudad? Segundo, ¿cómo se caracteriza la comunicación en las instituciones educativas y cómo se relaciona con la convivencia? Tercero, ¿de qué manera se relacionan los procesos pedagógicos de las instituciones, y, sobre todo, las prácticas docentes con la convivencia, la normatividad y el conflicto? Y, cuarto, ¿cómo se gestiona desde el punto de vista institucional la convivencia y cuál es la participación de las diferentes instancias institucionales en la misma? Como ya se sugirió, en este artículo se presentan los resultados relacionados con la segunda pregunta orientadora, es decir, con lo que atañe a los problemas de la convivencia en relación con los procesos comunicativos que tienen lugar en las instituciones educativas.

\footnotetext{
${ }^{1}$ Diego Herrera Duque (2001): Conflicto y escuela. Convivencia y conflicto. Caminos para el aprendizaje en la escuela, Instituto Popular de Capacitación (IPC) de la Corporación de Promoción Social, Medellín, pp. 9-10. Luis Fernando Duque (2000): Programa de Convivencia ciudadana de Medellín, Alcaldía de Medellín, Cargraphics, Foro Educativo por la Convivencia, Zona Noroccidental, Memorias, SEDUCA, Municipio de Medellín, Fundación Social, Corporación Región, 1996.

${ }^{2}$ La Red de Convivencia Escolar es una de las más importantes estrategias de trabajo interinstitucional e intersectorial de Medellín, constituida en 1997 con el objetivo de abordar los temas referidos a la convivencia escolar.
} 


\section{PROCESO METODOLÓGICO}

El presente estudio se ubica dentro de un enfoque cualitativo, desarrollado en dos fases metodológicas: una exploratoria y otra de focalización y profundización. La exploratoria, como su nombre indica, tuvo como propósito examinar el objeto de estudio con un elevado número de informantes clave (ver tabla 1), y recoger, mediante un cuestionario estructurado, las percepciones que sobre la convivencia escolar tienen diversos actores de las instituciones educativas de la ciudad. Dichos datos posibilitaron identificar y definir algunas tendencias características de la convivencia, desde la distribución porcentual en las cuatro categorías teóricas preestablecidas: convivencia, normatividad y conflicto; comunicación en la convivencia; los procesos pedagógicos y su relación con la convivencia; y la gestión institucional de la convivencia. Todo ello con el fin de iniciar la fase dos, de focalización y profundización de las tendencias definidas, apoyadas en entrevistas semiestructuradas y en talleres con estudiantes, con profesores, con directivos y con padres de familia, que fueron consultados para contrastar los datos recopilados en la fase uno (ver tabla 1 ).

TABLA 1

Población según rol institucional. Fase de focalización y profundización

\begin{tabular}{|l|c|c}
\hline Actor & Entrevistados & Participantes \\
\hline Rector & 0 & 1 \\
\hline Coordinador disciplina & 3 & 2 \\
\hline Director de grupo & 2 & 3 \\
\hline Profesor & 2 & 27 \\
\hline Personero estudiantil & 3 & 5 \\
\hline Estudiante & 3 & 65 \\
\hline Padre/madre defamilia & 2 & 30 \\
\hline Expertos de la Red & 6 & 0 \\
\hline Todal & $\mathbf{2 1}$ & $\mathbf{1 3 3}$ \\
\hline
\end{tabular}


Si bien el estudio se propuso ser descriptivo, se realizaron algunas interpretaciones que permitieron construir una perspectiva crítica y no sólo informativa en relación con el estado de la convivencia en las instituciones educativas. Eso posibilitó a la Red ampliar su horizonte de reconocimiento de la realidad escolar en lo que a convivencia se refiere. Dentro de las categorías previas aparecen unas emergentes, que son las que establecen el sentido que los actores educativos le han otorgado a la convivencia escolar, y de las cuales se da cuenta como parte de los resultados ${ }^{3}$.

\section{COMUNICACIÓN EN LA CONVIVENCIA ESCOLAR}

La categoría de comunicación se abordó en la fase exploratoria, de manera que se pudieron rastrear los siguientes asuntos o tópicos:

- La concepción de la comunicación como un aspecto de las relaciones interpersonales o de transmisión de información.

- La favorabilidad de la comunicación en la convivencia escolar.

- La utilización de canales de comunicación formales e informales.

- Las formas de comunicación utilizadas por los actores educativos.

- Las relaciones comunicativas entre los diferentes actores educativos.

A continuación se describen los procesos comunicativos en relación con la convivencia, a partir de las subcategorías emergentes.

\section{LA ESCUELA COMO CONTEXTO COMUNICATIVO}

La categoría de comunicación en relación con la convivencia está asumida desde la premisa de que aquella es una dimensión connatural a la vida social y cultural. Lo que sucede en la interacción

${ }^{3}$ Dentro de los resultados de la investigación se cuenta con el registro y la interpretación cuantitativa de la información, que no se incluyen en este artículo por límites de espacio. 
entre los actores educativos es comunicación. Las denominadas clases son eventos comunicativos cuya finalidad, en muchos casos, es la transmisión de información. La evaluación es un evento comunicativo en la medida en que se intercambia información en el interjuego preguntarespuesta. In fin, arando se adm ite desch la pragm ática ${ }^{4}$ que es imposible la incomunicación, se admite igualmente que también en la escuela todo habla. El acto pedagógico se la juega en todo momento al permitir expresar o reprimir los gustos o los disgustos, al compartir o no los sentimientos, las inclinaciones, las aspiraciones, los instintos y las necesidades materiales y vitales, y no sólo las ideas abstractas, las representaciones o las opiniones de maestros y de aprendices. Entonces, lo que la vida escolar afirma o niega es la comunicación humana, asumida como la interacción vital en igualdad de condiciones (reciprocidad) de ponerse en común en su forma más auténtica e ideal. Entender la comunicación como un asunto vital en la escuela entraña confrontar en todo momento el currículo explícito y el oculto, por cuanto en el aula y fuera de ella, en todos los demás espacios de la institución educativa, se aprenden y se enseñan a diario infinidad de comportamientos, de estilos de autoridad, de modas, de léxicos, de normas, de gustos de aceptación o de rechazo, de unión o individualismo, de inclusión o exclusión.

\section{MÁS ALLÁ DE LA ACCIÓN INSTRUMENTAL}

Siendo la escuela un escenario de la vida social, es necesario reconocer que los procesos educativos tienen un profundo carácter comunicativo, concepto muy noved oso como resultado de las reflexiones contemporáneas de las Ciencias Sociales y de la centralidad lograda en nuestra sociedad por los medios y por el tipo de cultura que inducen. Desde estas posturas se ha superado la visión instrumental que se tenía de los objetos de estudio. De forma específica en el campo de la educación, se manifiesta de manera clara y contundente esta visión instrumental en lo que se denominó hace unas décadas tecnología educativa. Ésta enfatizaba el modelo curricular del diseño de la instrucción, entendiendo la acción pedagógica como un conjunto de átomos (objetivo, actividad, evaluación) prediseñados, en los que el maestro era

\footnotetext{
${ }^{4}$ Dimensión de la lingüística que concibe el lenguaje y su uso en un contexto comunicativo específico, y en una relación particular de los interactuantes.
} 
considerado como un administrador del currículo y como transmisor de unos conocimientos mediante una relación - pedagógica- unidireccional con el estudiante. Desde esta concepción tecnicista, no se reconocían procesos como la socialización y las interacciones entre los estudiantes y los maestros, olvidando, por consiguiente, la tarea social de éstos como agentes de la cultura y como protagonistas de la formación de sujetos autónomos, responsables y solidarios.

Superada la perspectiva instrumentalista, se posibilita una mirada hacia un nuevo paradigma de educación, entendido como una práctica social intencionada en la que se orientan el desarrollo de las personas y la comunicación como los escenarios en los que la educación se concreta, y no sólo como los instrumentos a través de los cuales se transmite. La comunicación en el espacio escolar deja así de comprenderse como un conjunto de usos instrumentales dirigidos a generar ciertos aprendizajes escolares, para configurarse como el gran escenario en el que puede comprenderse, compartirse y construirse la vida escolar en todas sus manifestaciones, partiendo de las significaciones que cada uno construye sobre el mundo, y de las interacciones comunicativas en las que se forman órdenes de realidad. La comunicación, y sobre todo el lenguaje, permiten crear y recrear, construir y deconstruir las diversas maneras de pensar, de hacer y de sentir. Por eso, la comunicación no puede reducirse a un proceso informativo; las personas no sólo reciben y dan información, sino que construyen sentidos, es decir, que interpretan esa información que circula por sus mundos, que dicha interpretación está ligada a sus historias vitales, y, con ellas, a sus experiencias, a sus actuaciones, a sus intereses y a sus emociones. De ahí que, además de información, se comparten sentidos sobre el mundo. Si la escuela pretende compartir tales sentidos y construir una visión coincidente, eso implica superar la mirada lineal y reduccionista de entenderla como una identificación entre un emisor y un receptor. Más bien se les puede llamarperceptores, porque quien emite, en primera instancia, a la vez es afectado por un receptor-emisor de un sinnúmero de códigos no verbales-, que indica 0 muestra el efecto de su intervención, y, así mismo, pauta cómo reorientarla; al mismo tiempo, asumen dos roles y construyen en pareja un curso de comunicación, es decir, sus roles son complementarios, rotativos y simultáneos.

En la perspectiva instrumentalista aparece también la inclinación a percibir la comunicación en el centro escolar como un asunto de transmisión de información a través de medios como carteleras, circulares, memorandos o citas en momentos y horarios definidos por la 
institución. Los datos cuantitativos muestran una tendencia significativa, en la que la mayoría de los actores educativos percibe esta condición como aquella que impera y se sobrepone a la concepción de la comunicación como un asunto de relaciones interpersonales. De esta manera se ratifica el carácter normativo y formal que ha caracterizado a la institución escolar. Aunque predomina, como se ha dicho, una visión instrumentalista de la comunicación, parece que algunos profesores han superado esta visión, concediéndole un lugar significativo como un asunto de relaciones interpersonales y de construcción de sentidos.

\section{ENCUENTRO Y DESENCUENTRO DE CÓDIGOS}

Algunas de las investigaciones existentes ${ }^{5}$ sobre el tema de la comunicación han mostrado que los interactuantes, llamados perceptores, se interrelacionan mediante sus códigos, entendiéndose por código el lugar desde el que se emite yen el cual se percibe o se recibe un signo, o sea, que el código es el lugar específico en el espacio, en el tiempo y en la cultura desde el cual se desempeña el rol de perceptor. El código se ubica entonces en la cotidianidad de las personas.

El reconocimiento de códigos que identifican a los perceptores constituye tal vez la diferencia esencial entre los procesos informativos y los comunicacionales. La comunicación tiene como finalidad, en primera instancia, la negociación de códigos, perspectiva que, además de asumirla recientemente las Ciencias Sociales, los maestros también la rescatan en sus prácticas cotidianas. De ahí que, en las entrevistas realizadas a los actores educativos, aparezcan pronunciamientos como el que a continuación se cita:

[...] es importante aproximarnos a los estudiantes, y esa aproximación es, a veces, hasta buscando su propio lenguaje, para que no se sientan tan distanciados, a veces hasta preguntando por temas que pueden ser para uno superfluos, pero para ellos son de gran trascendencia como puede ser la rumba, la moda, el fútbol [... ] cuestiones muy cotidianas, que si uno se pone a conversar con ellos, ellos se explayan mucho y se sienten como muy identificados, en la medida en que uno está recibiendo su discurso (entrevista a director de grupo).

${ }^{5}$ J esús Martín-Barbero (2002): La educación desde la comunicación, Santafé de Bogotá, Editorial Norma. 
Si los códigos son el lugaren el cual se ubican los interactuantes, puede decirse que es desde allí desde donde cada ser se representa el mundo, y que es a partir de los códigos particulares que se puede aspirar a construir ambientes posibles para una convivencia civilizada. En otras palabras, estar en el código del otro implica re-conocerlo, ser capaz de asumirlo desde su propia identidad y particularidad. De ahí que se observe, partiendo de las encuestas, que las relaciones comunicativas entre maestros y estudiantes son las deseables y dignas para ellos, lo que supone una apreciable capacidad para el reconocimiento de códigos, y, como consecuencia, un reconocimiento entre sujetos. Por eso, y retomando las encuestas, se percibe la existencia de un ambiente comunicativo favorable para la convivencia escolar. Sin embargo, los padres de familia son vistos como los actores educativos con mayor incapacidad para el encuentro de los códigos de los que se viene hablando. En este mismo sentido son identificados los ex alumnos como los actores escolares con códigos comunicativos débiles o inexistentes con la institución escolar.

En la escuela, como institución social, se vive toda una gama de interacciones comunicativas; por ella transitan el diálogo, los consejos, las expresiones afectivas, pero también las humillaciones, las ridiculizaciones, los chismes, la «cantaleta», los rumores, la ironía, el sarcasmo, los anónimos y la agresión verbal, entre otras formas comunicativas. Los hallazgos de la investigación muestran que estas últimas formas de comunicación cotidiana no son usadas con mucha frecuencia, sobre todo entre estudiantes y profesores, y que se van convirtiendo en objetos de reflexión, lo que refleja una transformación favorable hacia la construcción de las interacciones en la escuela. A este propósito anota un director de grupo:

Aquí podríamos pasar como por distintos momentos de la institución, pero, entonces, para no mirar por retrovisor, como dicen ahora, en este momento la comunicación es muy buena, muy positiva, hay como un sentido no llamésmolo casual, sino que es producto de todas estas reflexiones que ha hecho todo el estamento docente sobre la necesidad de acercarnos mucho más al estudiante ${ }^{6}$.

Si bien las relaciones comunicativas se califican como buenas entre estudiantes y profesores, hay que destacar que no ocurre lo mismo entre los propios estudiantes, pues, según la información recogi-

\footnotetext{
${ }^{6}$ La cursiva es de la autora.
} 
da, formas comunicativas como la burla, el chisme y el rumor siguen teniendo una considerable presencia en las interacciones entre ellos. Los testimonios de los entrevistados hacen pensar que estas formas prevalecen como mecanismos de inclusión y de exclusión para tejer lazos de complicidad con los «parceros» y con los integrantes de las «galladas» a las que se pertenece, $y$, al mismo tiempo, como formas de diferenciación y de oposición con los «otros extraños». Los chismes y los rumores suponen un pacto que implica el compromiso de guardar el secreto de aquello que se comunica, y que se manifiesta en enunciados como «no se lo cuentes a nadie», «aquí entre nos», «cuidado vas a comentar», entre otros. Así mismo, y como muestran recientes investigaciones ${ }^{7}$ sobre el chisme y el rumor como mecanismos de crítica social, ellos suponen de los participantes un tipo de comportamiento más o menos ritualizado, que incluye, además del léxico, códigos kinésicos (miradas dirigidas y sostenidas, exageración de las expresiones faciales, apertura de ojos, sonrisas), proxémicos (ubicación en un lugar retirado, acercamiento de cuerpos, palmoteo), yacústicos (tonos de voz). Alrededor de estas formas comunicativas se teje lo más denso y cotidiano del conflicto y de la convivencia en la escuela.

Además de lo ya señalado en cuanto al mejoramiento de la comunicación, los testimonios de los entrevistados destacan que, desde hace poco, se observa en las instituciones educativas una ampliación de los tópicos conversacionales entre profesores y estudiantes, trascendiendo los temas académicos sobre otros de orden familiar y personal. Eso podría significar un fortalecimiento de los vínculos entre profesores y alumnos, que redundaría en un mejoramiento de los ambientes de convivencia. Aquí el diálogo amistoso y cálido no parece desdibujar el rol legítimo de autoridad del profesor, sino que, por el contrario, se le reconoce como un otro comunicativo y no como una figura coactiva.

En general, no hablan (se refiere a los estudiantes) de lo que uno quiera, no son reservados ni temerosos, ni marcan un límite o una distancia. Los temas son ilimitados, y si uno habla de intimidades con ellos, ellos son francos y a veces, a veces, demasiado. Plantean cuestiones de su vida personal, de su vida familiar, de su vida íntima (entrevista director de grupo).

\footnotetext{
${ }^{7}$ Gladys Acosta y Ángela Garcés (2002): «Un análisis pragmático del rumor a propósito de la columna: 'No nos consta' de Tola y Maruja», en Anagramas. Rumbos y sentidos dela comunicación, n.ำ1, jul.-dic., p. 70, Facultad de Comunicación y Relaciones Corporativas, Universidad de Medellín.
} 
La frecuencia con la que los profesores parecen tomar la iniciativa para instaurar la comunicación con los alumnos es confirmada por los padres de familia, quienes perciben las dificultades que tienen los adolescentes para superar el silencio en el ambiente familiar.

Los estudiantes no cuentan sus problemas, se guardan todo; no confían; el estudiante no tiene iniciativa de diálogo; el profe sí busca al muchacho, llama a la casa [...] muchos hogares tienen trastornos (entrevista padre de familia).

Aquí hay maestros con quienes los estudiantes conversan, no sólo pues de lo que es objeto de estudio en las clases, sino de sus vidas, de sus historias personales, de los problemas que tienen [...] con algunos hacen eso, con otros no. Pero sí es corriente que los muchachos hablen de sí mismos y quieran encontrar palabras que los acompañen (entrevista coordinadora disciplina).

Aunque hay profesores dispuestos al diálogo y a la escucha de la vida de sus alumnos, también se presenta el fenómeno contrario, esto es, la indiferencia, y, más allá, la negación de la existencia de un mundo diferente a lo académico en la vida de los estudiantes.

Yo sigo viendo mucho temor de los estudiantes a hablar; en algunos casos, esa es una cosa que a veces se pensaba que se había erradicado de la escuela; yo creo que no tanto (entrevista coordinadora de disciplina).

Sí, en eso, sí, pero dependiendo del profesor, porque no les interesa la vida de un estudiante, no les importa nada lo que le pase al estudiante. Mientras hay profesores que sí se interesan, le ponen atención, charlan con uno y lo aconsejan (entrevista al personero).

Además de lo anteriormente expuesto, y que muestra, por un lado, el mejoramiento de la comunicación en los escenarios escolares, también se registra un problema en la manera en la que algunos alumnos significan o desdibujan el rol de autoridad de los profesores, como resultado de la relación amistosa que estos propician a partir de comunicaciones más cercanas y de reconocimiento mutuo.

Vemos que hay estudiantes que tienen más confianza con algunos profesores, y dichos profesores dan ese espacio para que los estudiantes les confíen cosas que no tienen que ver con la academia, sino con la vida. Como hay otros profesores que no dan ese espacio. Como también es un arma de doble filo, porque los estudiantes, algunos estudiantes, no saben manejar esta situación. 
Que cuando el profesor les da confianza o quiere ser un amigo de ellos, entonces abusan. Entonces es muy delicado de manejar (entrevista a director de grupo).

Frente a este tipo de problemáticas, los profesores se muestran conscientes del riesgo que implica una comunicación que suponga el declive de su representación de la autoridad. Sobre eso, Carlos Mario González ${ }^{8}$ plantea que:

Ya he dicho que el adulto actual, por ejemplo, como padre y maestro, es vergonzante en su posición de agente de la ley. Muestra de ello es su ansiosa búsqueda de definirse como compañero de sus hijos o amigo de sus alumnos. Entonces el padre se destituye de su lugar, fantaseando ser un hermano de su vástago, y el maestro del suyo, según la fantasía de ser un amigo de su discípulo. Obviamente, cuestionar la supuesta fraternidad paterna, o la amistad profesoral, no es negar que entre padres e hijos o profesores y alumnos puedan y deban darse relaciones de diálogo, cordialidad y respeto, sino recabar en que padres y maestros, en tanto agentes de la ley, no son ni semejantes ni iguales a su prole y a sus discípulos.

Todas estas experiencias comunicativas, que tienen su asidero en la práctica social cotidiana, cobran un sentido particular cuando se trata de comprender las diversas maneras de convivir. Es fundamental reconocer que la comunicación es, ante todo, interacción; en ella y desde ella se intercambian conceptos, conocimientos, afectos positivos y negativos, valoración o irrespeto por los otros; se reconoce al interlocutor o se le ignora. En consecuencia, la comunicación se convierte de forma inexorable en el campo de las relaciones armoniosas u hostiles entre los actores educativos, se torna en el espacio de la convivencia posible. De allí que las prácticas comunicativas que transitan en la institución educativa, a la vez que propician la generación de conocimiento, la formación de valores y la interiorización de comportamientos, también inciden en la generación de conflictos, razón por la cual pensar en el mejoramiento de la convivencia escolar implica rescatar y revalorizar los procesos de comunicación inherentes a los procesos de aprendizaje, de socialización y de formación de actitudes democráticas, dialógicas y participativas.

\footnotetext{
${ }^{8}$ Carlos Mario González (1996): «Autoridad y autonomía», en Cuadernos Académicos, $n . \stackrel{0}{1}$, Medellín, Documento, Universidad Nacional.
} 


\section{LA APERTURA AL DIÁLOGO Y LA CONVERSACIÓN}

Los testimonios de los actores entrevistados muestran un viraje en relación con la conceptualización de la comunicación y con su importancia en las dinámicas escolares; parece, como ya se sugirió, que viene superándose la concepción instrumental de ella, en la cual la comunicación se asocia con la transmisión de información por medio de escritos como cartas, circulares, carteleras, avisos y el periódico mural, puesto que el grueso de la población entrevistada, aunque no la mayoría, destaca su importancia en términos de las relaciones interpersonales, de la participación de la comunicación verbal, y de la acción recíproca e interactiva que implica comunicarse cara a cara, reconociendo el diálogo reflexivo como una de las formas de comunicación más utilizadas en las instituciones educativas.

Los estudiantes señalan que, a pesar de que en sus ámbitos de barrio y familiares prevalece una incapacidad para el diálogo, en sus instituciones educativas se está abordando esta problemática como elemento clave de la convivencia escolar. Así, en las escuelas y colegios se empieza a percibir, en oposición a los contextos inicialmente mencionados, una apertura mayor para que los hilos de la conversación puedan ir y venir de uno a otro. En este sentido, y de acuerdo con lo que plantea Gadamer ${ }^{9}$, el fenómeno de la conversación, especialmente el diálogo entre dos, reviste gran importancia en la recreación de las culturas. Según este autor, ya desde el romanticismo y su renacimiento en el siglo $X X$, se asignó al diálogo un papel crítico en las voces de pensadores que han valorado la conversación, como Schleiermacher y Schelgel. Su preeminencia reside en identificar que, «cuando se encuentran dos personas e intercambian impresiones, hay, en cierto modo, dos mundos, dos visiones del mundo y dos forjadores del mundo que se confrontan». Así mismo, Platón afirmó en sus «Diálogos» que la palabra sólo encuentra confirmación en la recepción y aprobación por el otro, y que las conclusiones que no vayan acompañadas del pensamiento del otro pierden vigor argumentativo. Por ello, el diálogo con el otro, su aprobación o sus objeciones, los malentendidos, 0, por el contrario, su comprensión, permiten la ampliación de nuestra propia individualidad y una oportunidad para el despliegue de nuestra socialización. El diálogo permite, entonces, que los actores del proceso educativo creen ese género de

${ }^{9}$ Gadamer (1992): Verdad y Método II, Salamanca, Ediciones Sígueme, p. 203. 
comunidad, en la que cada cual es él mismo para el otro, porque ambos encuentran al otro y se encuentran a sí mismos en el otro ${ }^{10}$.

La conversación entre el maestro y el estudiante es, sin duda, una de las formas originarias de la experiencia dialógica; sin embargo, a pesar del mejoramiento en esta práctica pedagógica, existe en la situación del profesor una especial dificultad para mantener la capacidad de diálogo. Parece que el docente cree que en el acto de enseñar debe y puede hablar, y que cuanto más consistente, sólido y directivo sea su discurso, tanto mejor ejercerá el poder de comunicar su saber. Una prueba de ello es el siguiente texto:

De pronto, continuamos con ese [...] autoritarismo, donde el profesor sigue siendo la autoridad, el dueño del saber, donde «juntos pero no revueltos». Donde no se establece una verdadera comunicación. Donde la comunicación solamente se da en el aula de clases, solamente para llamar la atención, solamente para decir esto está mal hecho, haga esto, no haga esto, acorde a mis inquietudes, a mi forma de ser (entrevista director de grupo).

Este es uno de los rasgos más recurrentes en las prácticas pedagógicas de muchos maestros, y que de alguna manera genera rupturas entre su mundo y el de los estudiantes. No obstante, es importante aclarar que el diálogo o la conversación, como mediación pedagógica, tiene unos límites en las instituciones, que está determinado por el elevado número de estudiantes que se congrega en las sesiones académicas, y por su heterogeneidad. Esta complejidad del fenómeno comunicativo, en relación con la pedagogía, puede vislumbrarse a partir de lo señalado por Gadamer, parafraseando a Platón: «el diálogo no es posible con muchos a la vez, ni en presencia de muchos».

Los hallazgos de esta investigación muestran que el diálogo en las instituciones educativas de Medellín se presenta más como una opción en las relaciones interpersonales entre profesores y estudiantes fuera del aula, que como una alternativa pedagógica de los procesos de deliberación y de construcción del conocimiento en la misma, o, más aún, como la posibilidad pedagógica por excelencia. Sin embargo, algunos profesores intentan superar esta condición propiciando encuentros comunicativos más personalizados en el aula. El siguiente texto es revelador:

${ }^{10}$ Ibíd., p. 204. 
Sí, hay muchas maneras; por ejemplo, cuando estamos en un salón, habla (el profesor) para todo el grupo. Cuando se requiere hablar con un solo estudiante o con un grupo de apenas cinco personas, se habla con el grupo [...] dan muchas veces clases personalizadas en grupitos chiquitos. Esa es la comunicación básica (entrevista al personero).

Algunos estudios sobre la relación pedagogía-comunicación ${ }^{11}$ han mostrado que, mientras mayor sea la participación individual del estudiante en grupos o en organizaciones sociales, y mientras más se dé en ellos un diálogo abierto que permita la reciprocidad y la empatía emocional con el otro, más oportunidades tendrá de asumir las perspectivas sociales de los demás.

En relación con el diálogo el profesor se legitima con mayor fuerza, tal vez por su condición de adulto, de depositario de experiencia, de quien inspira confianza, en oposición a los mismos pares y compañeros del estudiante, que aparecen como incapaces de guardar secretos, de respetar la intimidad del confidente, de dar consejos, y de aportar salidas reflexivas ante las problemáticas del estudiante. Uno de ellos anota:

Pero en ocasiones en que el estudiante tiene cierto grado de confianza en el profesor [...] sabe que puede encontrar en él un apoyo, y sabe que puede confiar en él. Porque si tenemos en cuenta que somos jóvenes y que le comentamos a otros nuestros problemas, lo mínimo que puede hacernos es gozarnos, o decir que nos guardan el secreto y comentarle a los otros; entonces es muy maluco, entonces para algunos estudiantes [...] pienso que es mejor comentarlo con una persona madura porque sabe recibir la noticia, y porque sabe qué es lo que la otra persona le está diciendo y cómo se lo está diciendo (entrevista a estudiante).

El anterior texto permite reconocer un elemento fundamental que aparece en las encuestas, como una variante dialógica de los maestros y como algo muy valorado por los estudiantes: el consejo. Este supone una experiencia de diálogo amistoso, pero asimétrico, pues da lugar al poder del profesor, quien aparece legitimado por su experiencia para proveer posibles salidas y soluciones frente a problemas que le plantea el alumno. Este último reconoce un poder moral en el profesor, que hace pertinente su lugar con una palabra que acompaña, que orienta y que muestra posibilidades de actuar.

${ }^{11}$ Horst Nickel (1981): Psicología de la Conducta del Profesor, Barcelona, Editorial Herder, p. 88. 
Por otra parte, el diálogo aparece asumido como un mecanismo de reflexión para la toma de conciencia por parte del estudiante, para su formación, para el discernimiento de las consecuencias de sus propias actuaciones y de sus repercusiones en las relaciones con los otros.

Sí, yo creo que sí. Por lo menos es lo que procuramos permanentemente $[. .$.$] ante cualquier conflicto que se presente;$ antes de sancionar se pueda hablar, se pueda discernir que fue lo que pasó, y ofrecer como elementos para que cada cual asuma sus responsabilidades frente a la situación. Te digo que muchas veces sucede eso, seguramente que habrá ocasiones en las que no, los profesores siguen manejando los cuadernos de disciplina, por ejemplo, y ahí la preocupación fundamental es hacer la anotación; entonces no hay un más allá de la anotación, no hay una conversación sobre lo que pasó, y en muchas oportunidades o la indicación general es que se converse... por lo menos desde la Coordinación, yo siempre procuro que antes de sancionar pueda haber una conversación entre las partes implicadas en un problema, pues que los muchachos puedan conversar sobre lo que pasó. Porque yo creo que esa conversación puede tener efectos (entrevista coordinadora disciplina).

Son muchos los alumnos que rescatan esta dimensión interactiva que posibilita el diálogo, para compartir con el profesor las aflicciones y las problemáticas personales, así no exista la posibilidad de encontrar una solución, pero sí un otro dispuesto a escuchar.

[... ] pues no necesariamente con el fin de que el profesorado se los solucione (los problemas familiares y personales del estudiante), porque uno está como en muy poca posibilidad de llegar a resolver ese tipo de problemas familiares tan de fondo, pero el hecho de que uno los escuche, de alguna manera ellos se sienten aliviados, como teniendo con quien compartir esas circunstancias $[\ldots$ ] en la medida en que ellos se manifiesten, pero, sin embargo, siempre queda la pregunta de hasta dónde puede uno resolver esos problemas (director de grupo).

El diálogo, y más si se asume de manera reflexiva, implica en los escenarios escolares la posibilidad de la negociación y la concertación de reglas de juego y de dinámicas formativas que se asumen colectivamente, lo que implica un viraje hacia el intercambio simbólico, en el que los interlocutores se aproximan unos a otros. Se trata, sin duda, de una forma de praxis social que contribuye en gran medida a construir la «comunidad imaginada» que representa el escenario escolar. El éxito de esta negocia- 
ción está en la condición decisiva de saber ver al otro como «otro», y en el compromiso que genera ser tenido en cuenta por los demás.

En este caso, los intereses reales del otro que contrastan con los propios, percibidos de forma correcta, influyen quizá en las posibilidades de convergencia y en la realización de objetivos y de tareas comunes. EI encuentro con el otro se produce sobre la base de saber autolimitarse, y, más aún, cuando se trata de intereses de poder. El rol del docente también exige reconocer que existe un tiempo en el que debe callarse, pues la escucha también lo implica a él, para identificar que sus alumnos son sujetos que tienen algo que decirle, pues tienen voz propia.

Aun reconociendo desde la teoría de la comunicación estos elementos, se observa con reiterada frecuencia la dificultad que enfrentan las personas para construir maneras comunicativas accesibles a los otros; tal vez ello resida en la diversidad de representaciones que se dan sobre la realidad, pues existen tantas maneras de concebir el mundo ysus problemáticas como sujetos. Al respecto, Mariluz Restrepo afirma que:

Si algo caracteriza este siglo es un desplazamiento hacia el mundo del simulacro. Ya no sólo representamos sino que simulamos realidades, y esto pone en crisis la noción de realidad [...] la aparición de sensibilidades nuevas, en donde estamos simultánea y paradójicamente viviendo lo uno y lo múltiple, lo plural. Por un lado, se vislumbran las tendencias otra vez hacia los reduccionismos, hacia la unificación de criterios, y, por otro lado y simultáneamente, se plantea una búsqueda y una pelea de la multiplicidad de la diversidad, de la pluralidad, de lo que no tiene un solo camino ${ }^{12}$.

Podríamos pensar que gran parte de los conflictos en la cotidianidad escolar responden al no reconocimiento de la multiplicidad de caminos que tenemos a la hora de representarnos aparentemente una misma realidad; quizás esta sea una forma de comprender por qué para al gunos de nuestros actores entrevistados el camino hacia la convivencia y el mantenimiento del orden y la disciplina es aceptar la suprema presencia de la norma sin ser cuestionada, y, para otros, la posibilidad de la discusión y de la confrontación de esas mismas normas, aún en el marco de las interacciones que ellas propician.

12 Mariluz Restrepo (1996): «Nuevos modos de comunicación entre los individuos de la organización», en Simposio Latinoamericano de Comunicación Organizacional, Memorias, Cali, Universidad del Valle. 
La vivencia en los espacios cotidianos puede responder a las fisuras comunicativas que se presentan cuando somos incapaces de respetary de manejar las diferencias, y de asumirlas sin atropellar al otro. Sobre estos aspectos de la comunicación, Restrepo sugiere que:

La idea es aceptar que todos hacemos parte de una red múltiple, laberíntica, diversa, de posibles caminos y rumbos. Esto supone estar de acuerdo con una categoría que para mi es fundamental, y es que la comunicación es conversación, es la posibilidad de generar un diálogo capaz de abrir sentido, de transformar y no necesariamente de generar consenso.

\section{MEDIOS DE COMUNICACIÓN Y CONVIVENCIA ESCOLAR}

Por lo demás, y como otra de las formas comunicativas vigentes en nuestra sociedad y en la realidad escolar, aparecen los medios de comunicación. A partir de las entrevistas realizadas a los actores escolares, se observa que los medios son una manera de agenciar lo cultural, más que un conjunto de nuevos aparatos y de sofisticadas máquinas. Se trata de «objetos culturales» que designan nuevas sensibilidades, de otros modos de percepción, de relacionarse con el tiempo y con el espacio, de nuevas maneras de socializarse y de convivir.

Los medios marcan un reto cultural para la escuela, que muestra la amplia brecha que se abre entre la cultura desde la que enseñan los profesores y aquella desde la que aprenden y vivencian a diario los estudiantes. Los medios constituyen un ámbito decisivo de socialización, de dispositivos de identificación y de proyección de pautas de comportamiento, de estilos de identificación y de patrones de aceptación y/o de rechazo.

Hoy se puede apreciar cómo emerge una nueva generación, y cómo se construye no ya a partir de figuras, de estilos y de prácticas tradicionales, sino a partir del juego de la conexión-desconexión con los aparatos. El presente estudio sugiere cómo los jóvenes están dotados de una elasticidad cultural ${ }^{13}$ que podría interpretarse como una falta de

\footnotetext{
${ }^{13}$ J orge Silva (1998): «La transformación de los contextos comunicativos: un desafío para la educación actual», en Magistrales, México, Universidad Iberoamericana, enero-junio, pp. 66-67.
} 
forma, pero que, por el contrario, podría corresponder a la apertura, a una multiplicidad de ellas. Dicha plasticidad les confiere una adaptación a los más diversos contextos, y una gran facilidad para manejar los lenguajes de las tecnologías. En este sentido, abordar los procesos de socialización y de convivencia dentro de las instituciones educativas no puede ignorar la estrecha relación entre estos y los modelos de comportamiento pautados a través de los medios masivos de comunicación. Más que pensar en sancionarlos o en satanizarlos, la escuela se enfrenta al hecho de reconocer que están ahí, frente a nosotros, y que van ganando presencia día a día. Es pertinente aclarar que la escuela tiene un peso mayor en la transmisión de los contenidos científico-disciplinares y en el aprendizaje de los códigos tradicionales, pero los medios de comunicación lo tienen en el aprendizaje de las funciones de los objetos de la sociedad moderna, de los roles sociales, de las relaciones cotidianas y de la moral de las nuevas generaciones. Aquí se asiste a un desfase de dispositivos culturales, pues parece que mientras el profesor enseña para acumular conocimientos, los medios determinan formas de actuar, y es ahí donde los asuntos de convivencia se nos plantean desde una dirección diferente. Los profesores han captado, a su manera, la complejidad de esta problemática y las implicaciones que tiene para la socialización en la escuela:

[...] los medios de comunicación, que, aunque son necesarios, muchas veces [...] borran con el codo lo que nosotros hacemos con la mano. Porque los medios de comunicación en los ejemplos nacionales y extranjeros lo que muestran es la envidia, lo que muestran es la violencia, lo que muestran es la trampa; eso se puede volver un modus vivendi, y ellos se creen que esa es la forma de vida. En esa medida repercute mucho todo lo que es el entorno en la institución, y uno podría creer que el colegio es un oasis donde se plasma una condición ideal de una juventud que muchas veces afuera no se puede realizar (entrevista director de grupo).

Resulta contradictorio que los docentes reconozcan la gran influencia que tienen los medios masivos de comunicación en la cultura escolar, y, sin embargo, en los espacios educativos se acuda tan poco a ellos, no sólo para reflexionarlos críticamente, sino, y sobre todo, para convertirlos en mediaciones potenciadoras de la convivencia institucional y social.

Se asistea un problema que desborda el escenario institucional, pues el papel que cumplen y han cumplido los medios, y, en particular la televisión, con respecto a la familia y a la escuela, trae aparejado un 
desorden cultural que descompone las formas de autoridad vertical entre los jóvenes, sus padres y los maestros. Como ha sugerido J esús MartínBarbero, la televisión «deslegitima» y «deslocaliza» las formas continuas del saber promovidas en la escuela desde el texto escrito, que constituye el centro de un modelo lineal mecánico basado en aprendizajes graduales de acuerdo con las edades evolutivas del niño. Por medio de la televisión el joven accede rápida y cómodamente a un saber visual que subvierte el modelo escolar por etapas, legitimado por la autoridad del maestro. Trasladada al hogar, la televisión cortocircuita las relaciones de autoridad entre padres e hijos, al permitir que estos últimos accedan por su propia cuenta al mundo que antes les estaba vedado, el mundo de los adultos ${ }^{14}$. De esta manera, los medios han venido a recordar que, antes de que los aprendizajes adquirieran la forma escuela, los niños se encontraban entremezclados con el mundo de los adultos, sin los escrúpulos ni los cuidados con los que hoy se les trata, y aprendiendo los códigos culturales por medio de prácticas sociales bastante versátiles y efectivas.

\section{CONSIDERACIONES FINALES}

El recorrido que se ha realizado en estas páginas lleva a pensar que no es clara en absoluto la situación de la comunicación y su relación con la convivencia escolar, pues así como hemos encontrado testimonios y percepciones que dan cuenta de los ambientes favorables a ella, también se aprecian versiones contrarias que afirman que todavía la comunicación está por ser una posibilidad para la convivencia civilizada. No obstante, y a pesar del panorama desalentador sobre la situación de la convivencia escolar en Medellín que muestran investigaciones realizadas antes que la nuestra, es justo reconocer, como se pudo observar en este estudio, que los profesores, los estudiantes y los padres de familia han desplazado su mirada hacia la comunicación, asumiéndola no sólo como una acción cotidiana inconsciente, sino como objeto de reflexión y de intervención. Se reconoce que aún estamos muy lejos de abordar la

\footnotetext{
${ }^{14}$ J esús Martín Barbero (1996): «Heredando el futuro. Pensar la educación desde la comunicación», en Nómadas. Comunicación y educación: una relación estratégica, Santafé de Bogotá, n. 5, septiembre, p. 14. José Manuel Pérez Tornero (2000): «Las escuelas y la enseñanza en la sociedad de la información», en J osé Manuel Pérez Tornero (comp.) Comunicación y educación en la sociedad de la información, Barcelona, Paidós, pp. 37-57.
} 
comunicación como un problema dialógico que compromete profundamente lo pedagógico, y a la que todos estamos Ilamados a valorar como un espacio que merece la conciencia necesaria para poder mejorarla, $y$, con ella, la convivencia escolar. Con independencia de las adversidades económicas, sociales y políticas propias de los países latinoamericanos, existe la convicción, en muchas de las escuelas de nuestras ciudades, de que es posible generar espacios en los que la comunicación permita el reconocimiento de sí mismo y del otro, y de que es través de ella desde donde podrán desplegarse estrategias, iniciativas y pautas creativas con respecto a la convivencia ciudadana.

\section{BIBLIOGRAFÍA}

CORPOEDUCACIÓN (2001): Situación de la educación básica, media y superior en Colombia, Bogotá, Casa Editorial El Tiempo, Fundación Corona, Fundación Antonio Restrepo Barco.

Correa ValderRama, S., y otros (2000): La escuela como cátedra, vida de convivencia y paz, Medellín, Secretaría de Educación y Cultura de Antioquia, SEDUCA.

CUBIDES, J. H., y otros (eds.) (1998): «Viviendo a toda». Jóvenes, territorios culturales y nuevas sensibilidades, Bogotá, Fundación Universidad Central-Siglo del Hombre Editores.

DAZA, A. (comp.) (2001): Experiencias de intervención en conflicto urbano, Seminario realizado por el Programa de Convivencia Ciudadana de la Alcal día de Medellín, La Oficina del Alto Comisionado para la Paz y Comfama, 25-27 de noviembre de 1998, 2 tomos, Ediciones Gráficas.

DUCHATZKY, S. (1999): «La escuela como frontera. Reflexiones sobre la experiencia escolar de jóvenes de sectores populares», Buenos Aires, Paidós.

NARANjo Giraldo, G., y otros (2001): Ciudad y ciudadanía. Bajo la lente del conflicto urbano, Medellín, Corporación Región.

Naranjo Giraldo, G. (1992): Medellín en zonas. Monografías, Medellín, Corporación Región.

PROSPECTIVA Y DESARROLLO LTDA. (2002): Diagnóstico sobre la situación actual en materia de convivencia de las instituciones educativas de la ciudad de Medellín, Medellín, Red de Convivencia Escolar.

URIBE DE HINCAPIÉ, M. T. (1994) «Medellín: diagnóstico y situación actual», en Medellín en paz. Plan estratégico de seguridad para Medellín y su Área Metropolitana. Medellín para todos, Medellín, Alcaldía de Medellín. 


\title{
REVISTA IBEROAMERICANA DE EDUCACIÓN
}

\author{
REGRESAR A ÍNDICE № 37
}

REGRESAR A PÁGINA INICIAL DE LA REVISTA

CONTACTAR 